\title{
Researching prior learning: How toddlers study movies
}

\author{
Cary Bazalgette* - UCL Institute of Education, UK
}

\begin{abstract}
Taking issue with Bergala's dismissal of students' prior learning, disdain for popular culture and implicit preference for film education as a secondary school subject, this paper argues for the importance of studying children's earliest encounters with both films and television (summarized as 'movies'). The research described here was based on the hypothesis that a learning process must be under way in these encounters, enabling children to follow much of the multimodal complexity of mainstream feature films by the time they are 3 years old. A longitudinal, ethnographic study of the researcher's twin grandchildren between the ages of 22 and 31 months used video to capture phenomena such as focused attention, repeat viewing, emotional responses, utterances and gestures. Analysis, using embodied cognition as well as sociocultural approaches, revealed the extent to which 2-year-olds are starting to follow, enjoy and reflect upon movies well before they can understand the words in their songs and picture books. The findings have implications not only for film education with older students, but also for early years research, and for the production of movies aimed at this age group.
\end{abstract}

Keywords: ethnography; 2-year-olds; embodied cognition; television; film

\section{Introduction}

As an educator, I am interested in learners' biographies. All learners - even newborns - bring prior experiences to the learning processes on which they embark. If we want to encourage and support these processes, we need to understand what learners are bringing with them. Without reverting to the now widely discredited concepts of 'ages and stages' and 'learning readiness', we can acknowledge that the prior experiences of, say, 6-year-olds are likely to differ in many ways from those of 14-year-olds. In the research that I shall describe in this paper, I sought to identify features of the very early stages of children's film education by studying 2-year-olds' engagements with moving images. Using evidence from some of my findings, I argue that discussing and planning film education with any age group could be enhanced by recognizing the very long learning process that learners have already accomplished, and by respecting the interests and preferences that this process may have generated. My approach is thus very different from that of Alain Bergala.

\section{Bergala's approach to film education}

Bergala has a dismissive attitude to much of students' prior learning about film. In his British Film Institute (BFI) talk, he implies that, outside the classroom, learners have never 'watch[ed] films, or clips from films, several times, and create[d] connections 
between them'; instead they are in the habit of 'flitting unconsciously from one thing to the next' and surfing YouTube 'with nothing to link these random clips together, leaving very little or no trace at all on the memory of the surfer' (Bergala, 2017). He claims that we delude ourselves if we believe 'that young people can build up a relationship with cinema without the direct involvement of someone to start them off'. These are all assumptions that are contradicted by my research findings. However, at the same time Bergala proposes pedagogic techniques that do acknowledge students' prior experiences of film, in recommending an initial session in which:

it is the students who speak first, exchanging their perspectives and ideas on what they've seen in the excerpts. It is only after this first, horizontal exchange between the students themselves that the teacher takes over, with their own knowledge and perspective on culture, but only after the core ideas have been identified by the students, in response to the experience of seeing these excerpts (Bergala, 2017).

This implies that students do bring their own critical perspectives to the film extracts that they initially see in class, but Bergala has little to say about these perspectives or how they may have developed.

Of course, Bergala's project is firmly ensconced in the classic French and Eastern European tradition of 'a true induction to cinema', aiming to instil a love for cinema as an art form, completely distinct from television, which he sees as merely the bearer of 'communication and ideology', dismissing the idea that film and television have any common ground (ibid.). From this perspective, film education would inevitably become a specialist subject, probably only in secondary schools: fine as far as it goes, but extraordinarily limited in relation to organizations such as the BFI or the $\mathrm{UCL}$ Institute of Education, both of which have a much wider remit for education about moving-image media.

Implicit in Bergala's position is a disdain for popular culture. While I am wary of the vast generalizations that underpin many deployments of the term 'popular culture', the arguments made by scholars in favour of addressing young children's engagements with it are similar to mine in emphasizing that we must not neglect the 'prior textual experience' that children have acquired in their early engagements with popular cultural forms (for example, Kissel, 2011; Marsh, 2000; Shegar and Weninger, 2010). They work, as I do, within the much-longer educational tradition of respecting learners' own cultures as an essential basis for teaching (Freire, 1970; Richmond, 2017). In the course of my research, however, I have also become interested in the evolved, instinctive behaviours that have important roles in learners' social, cultural and intellectual development, and that are particularly evident in 2-year-olds.

\section{Background to my research}

Most teachers in nurseries and primary schools are initially resistant to the idea of teaching about moving-image texts - which, for the sake of brevity, I am calling movies - (following Noel Carroll, 2010), if only in terms of likely parental attitudes, and the anxieties about the possible risks of movie-watching that dominate public discourse. In my experience, these concerns evaporate when teachers permit themselves to watch and discuss movies with children. They recognize the significance of movies in children's lives, and the learning that has been involved in their viewing practices at home. It transforms their assumptions about what children know and can do, and thus changes their expectations (Parry, 2013). Throughout my professional career, 
I was continually struck by teachers' almost invariable amazement at the high levels of confidence, articulacy and skill demonstrated by children when they are enabled to analyse or make movies. This happened consistently, whatever the age of the children being taught: Whitney (2010), for example, describes 3-year-olds in a Lincolnshire nursery school, responding to and discussing the short film Baboon on the Moon (Duriez, UK, 2002). By the end of the 1990s, I felt confident that children must be learning to understand movies at a very early stage in life, and that this could be an important factor in their later learning.

My doctoral research, which began in 2011, was based on the hypothesis that during their second year of life, children who watch movies must have begun to understand the strategies that moviemakers use to present characters, to establish diegeses and to construct narratives, and that this understanding must progress dramatically in their third year, given that most can enjoy much of a mainstream feature film by the time they are 3. This hypothesis provides an alternative to the working hypotheses that underpin most research on children and movies, and indeed moviemakers: that as an iconic medium (Pierce, quoted by Wollen, 1998: 83), movies constitute 'a message without a code' (Barthes, 1977: 17) - that therefore we interpret them easily, on the basis of our perceptions of the real world. But if movies really are that easy to understand, children in the age group that I have studied would probably not be expending time and effort in viewing and re-viewing movies with the same amount of extreme concentration each time. Nor would they ever choose to watch movies that challenge their capacity to understand them. Film theory recognizes the immensely complex, multimodal nature of movies, and has by no means finished arguing about what 'making sense' of a movie actually does mean, but it does recognize that movies are not automatically understood. So rather than categorizing re-viewing behaviour - as most parents do - by either using the language of affect (as in, 'he really loves it') or by quasi-medical terms (as in, 'she's just addicted to it'), we could instead be investigating it on the basis of a hypothesis that it could be part of the evidence that a learning process is under way. It may well never be possible to identify and assess this learning process in the same way that we may be able to comment on a toddler's increasing verbal fluency, certify an 8-year-old's competence in riding a bicycle, or mark a 14-year-old's maths exam. It is a learning process that we can only infer through evidence of a child's ability to follow an extended movie narrative, such as laughter or tension, and through the questions they may ask and the comments they may make.

To investigate children's early engagements with movies thus invites analogies with the 'astonishing feat' (Britton, 1970: 37) of language learning, but this analogy can be pushed too far. The question in Branigan's book Narrative Comprehension and Film - 'when and how do children understand an eyeline match, screen direction, crosscutting, an unusual angle, off-screen space, or non-diegetic sound?' (Branigan, 1992: 225) - underpins many futile efforts by teachers to justify film education by arguing that movies literally have a language whose features can be matched with those of verbal language. We do better simply to recognize that the multimodal complexity of movies means that learning how to watch them may also be an astonishing feat, undertaken at the same time as language learning, but with nothing like the same level of support and reinforcement that children receive in their learning of verbal language.

\section{Research questions and design}

Based on the hypothesis that 2-year-old children must be learning how to make sense of movies, my research aimed to find out whether convincing arguments could 
be made for this on the basis of observing and analysing children's behaviour and utterances as they watch. Given that most 2-year-olds lack verbal fluency and usually show heightened interest in - or anxiety about - the nature of any new situation, I do not believe that valid, generalizable evidence of such learning will ever be gained through experiments, interviews or tests, as in 'the science of the strange behavior of children in strange situations with strange adults for the briefest possible periods of time' (Bronfenbrenner, 1977: 513). My focus was on 'the natural process by which children need to master cultural knowledge' (Trevarthen, 2005). Indicators of this process are most likely to be gathered in contexts where children are relaxed and often in the company of known family members. In other contexts, there are too many new things that toddlers must pay attention to, and, in any case, the sociable nature of family viewing makes a vital contribution to the cultural dimensions of the children's learning about movies. Therefore I decided (with their parents' permission) to study my twin grandchildren from the age of 22 months. There was a period of intensive fieldwork studying the twins' viewing behaviour up to 31 months, mainly through using video to document as many occasions as possible when the children were watching movies, but also through direct observation of their movie-watching, as well as some of their other play and talk, documented in field notes.

As Rowe (2008) indicates, ethnographic studies of 2-year-olds are rare, and Lealand (1998: 4) points out that 'among the thousands of research studies and policy statements on children and television, viewers under 5 years old are usually underrepresented and often ignored', despite general acceptance of the idea that the early years are the most formative. Such studies inevitably involve 'practical and logistical considerations including gaining access, involving children as active research participants and negotiating consents' (Plowman and Stevenson, 2013: 330). But gaining access and consents are only part of the problem: it is also necessary to design research strategies that can capture what Lemish and Rice (1986: 267) call 'the richness of the interactions surrounding the television experience', but which to many people just looks like chaos.

Nevertheless, many scholars have pointed out that longitudinal, home-based, ethnographically styled research is essential if we are to gain a fuller understanding of very young children's engagements with media, given that these typically take place in the home environment (Hancock and Gillen, 2007; Jordan, 2006; Moses, 2008; Plowman et al., 2012; Rowe, 2008; Storm-Mathisen, 2016; Thomson et al., 2012). I saw the possibility of undertaking a case study of my own grandchildren as a unique opportunity to address my research questions in a context that was the nearest possible equivalent to what Plowman and Stevenson (2013) call 'the quotidian in young children's lives at home'. The fact that the children concerned were girl and boy dizygotic twins was an added advantage, in that I did not have to deal with the dynamics of relationships between siblings of different ages, or with the particularities of monozygotic twins, but might have some opportunities to consider gender differences. There are, of course, potential drawbacks in studying people within one's own family, but I believe that the advantages outweigh them, and I was, in any case, following in some distinguished footsteps: Darwin (1877), Piaget (1929), Britton (1970), Weir (1970) and Halliday (1975) all studied children they knew well, in familiar home settings.

\section{Theoretical perspectives}

Sociocultural perspectives on children's learning and development, including their relationships with media, were helpful to me in exploring the convivial and often 
boisterous family viewing events that I had recorded. There was always at least one adult (me) with the children in the viewing events that I recorded and observed, and often two or three, especially in the earlier phase of the fieldwork. It seems probable that the adult presence contributed in important ways to the children's developing understanding. The adults' voices contributed to the aural ensemble of movie soundtracks, murmured reactions to the movies, direct address to the children and conversation among themselves, which at some points may have directed the children's attention or supplied ready interpretations. But the adults' behaviour also continually modelled their attitude to movies, including how they should be watched, the existence of personal preferences, and the cultural values attached to them. This undoubtedly contributed to the children's expectations of the movies they watched. In addition, sharing pleasurable moments and achieving shared interpretations sometimes after initial misunderstanding - were immensely enjoyable and satisfying, and thus played an important role in the family's sense of solidarity and identity.

But in considering the children's intensely physical and often idiosyncratic responses to what they watched, the sociocultural perspective was less helpful. Embodied cognition approaches, with their emphases on the complexities of perception and on instinctive, evolved behaviour, offered me illuminating ways of analysing the physical details of what initially appeared merely as 'being attentive'. I found embodied cognition to be particularly helpful in studying 2-year-olds' responses to movies, prompting me to explore further the emotions that were expressed through the children's bodily expressions and postures in many of the viewing events I observed and filmed. For example, my initial interest in the children's fearful reactions to apparently innocuous material was based on the supposition that these indicated the children's 'mistaken' interpretations of what they were watching, such as being unaware of generic features that were supposed to signal humorous intent. But this seemed to disregard the intensity and longevity of these responses. I was intrigued to realize that Darwin's speculations about his son (aged 27 months) when he reacted to seeing large animals in cages at the zoo, anticipated later discoveries in neuroscientific research that connect emotions to survival in early evolutionary periods:

He often said afterwards that he wished to go again, but not to see 'beasts in houses'; and we could in no manner account for this fear. May we not suspect that the vague but very real fears of children, which are quite independent of experience, are the inherited effects of real dangers and abject superstitions during ancient savage times? (Darwin, 1877: 288)

The neuroscientist and psychobiologist Panksepp (2004) describes emotional operating systems in the brain, making the same link, minus the judgemental note of 'abject superstitions'. His argument is based on the proposition that 'all mammals possess intrinsic psychobehavioural control systems' that, from birth, enable them to start learning and to survive (Panksepp, 2004: 25). He focuses first on the 'powerful, primal emotional circuits', which are the ones 'that appear to elaborate fear, anger, seeking and sorrow'. I was particularly interested in his account of the 'seeking' emotion as an early survival mechanism: essential to feelings of engagement and excitement, it generates anticipation and investigation, not only in doing things like foraging and finding shelter, but also 'gradually helps cement the perception of causal connections in the world and thereby creates ideas' (Panksepp, 2004: 144-9). 


\section{Neuroscience, emotion and embodied simulation}

A useful note of caution - as well as an implied call for further research - is provided by the American neuroscientist Damasio (2000), arguing against the idea that we have a 'biological machinery' that is 'preset' to deliver predictable emotions, cognition and behaviour. This idea has been resisted by most sociocultural scholars but is now in any case superseded in neuroscience, as Damasio explains:

In all probability, development and culture superpose the following influences on the preset devices: first, they shape what constitutes an adequate inducer of a given emotion; second, they shape some aspects of the expression of emotions; and third, they shape the cognition and behaviour which follows the deployment of an emotion (Damasio, 2000: 127).

Recognizing the role of emotion in driving action and cognition illuminated my analysis of these 2-year-olds' behaviour, particularly their phases of intense concentration, in which one or other of them, or occasionally both, would display physical signs of focused attentiveness, such as bodily tension, frowns and cheek-chewing as they watched intently for periods of up to ten minutes. This attentiveness rarely bore any relation to what the co-viewing adults were saying or doing. The fact that they were selective, and increasingly so, both about what movies they each chose to watch and on what movies - or parts of movies - they each decided to focus their attention, was an important early finding. It generated questions about what aspects of those movies attracted them and, in many cases, led to numerous repeat viewings. While it is extremely difficult, and perhaps impossible, to find out with any certainty what drives a child's movie preferences before she has developed intelligible speech, it was noticeable that the twins invested their most intense attentiveness, and sustained reviewing, in material that seemed to be offering them hermeneutic challenges, such as movies they had never seen before, and movies that were stylistically distinctive. This included mainstream children's television just as much as non-mainstream movies (for example, from some of the short film anthologies published by the BFI in the early 2000s). I therefore do not see re-viewing merely as a search for reliving the enjoyment of the previous viewing: it can plausibly be regarded as a search for further meaning (which is clearly also enjoyable). This would then imply that in the initial viewing they understood some things, but were aware that there was more to discover, and did not find this frustrating or baffling.

The concept of embodied simulation, based on the discovery of mirror neurons (Gallese and Sinigaglia, 2011), modifies the somewhat individualistic approach of embodied cognition, and opened up key dimensions of this project, not only in considering the social context of viewing, but also in recognizing the role of moviewatching in modern human ontogeny. Embodied simulation characterizes the ways in which humans instinctively attempt to identify and assess other people's emotions, intentions and actions (Gallese, 2001; Gallese and Lakoff, 2005; Gallese and Sinigaglia, 2011). 'Simulation' in this context does not mean pretence or imitation, but the process of modelling an event or activity in order to understand it better. This potentially casts new light on the ways in which all humans mimic other people's expressions and gestures, often unconsciously: while some adults may comment on this as merely 'cute' in infants and toddlers, it can more usefully be interpreted as a way of 'trying out' the feelings that the bodily phenomena are expressing, and can relate to characters on screen as well as to real people. It may thus be a significant element of children's learning 
to follow narrative, when they recognize, relate to and imitate expressions, gestures and postures of characters in movies, and sometimes also those of people watching with them. It is particularly relevant in the study of 2-year-olds, given that their linguistic fluency and ability to follow narratives are still developing. We may thus see emotions as the drivers, and embodied simulations as the mechanisms, by which very young children can start to follow and enjoy movie stories well before they can understand the words in their songs and picture books, demanding repeated re-viewings until they have 'used up' a movie and seek further pleasurable challenges elsewhere. I see the early learning enabled by children's intensive - and often self-directed - viewing and re-viewing of movies as closely integrated with their learning about the medium and its role in their family life. Immensely complex and idiosyncratic processes can be at work in a 2-year-old's initial encounter with a movie they have not seen before. There are endless possibilities for what salient features a child might select, and what might spark their initial commitment to see, hear and find out more. Lancaster's (2001: 136) phrase 'an expectation of significance about the symbolic systems they encounter', although she applies it to drawings, not movies, helpfully characterizes much of what goes on in these initial viewings.

\section{Comprehension and modality judgements}

Many developmental psychologists' studies of children and movies are concerned first and foremost with cognitive engagement and comprehension, assuming that if children do not understand what they are watching, then they will lose interest. There is little acknowledgement of the possibility that partial understanding could drive reviewing. By accepting the importance of emotion in generating attentiveness, and by adopting a wide view of what emotions are and how they function, my analysis of the children's viewing revealed more and more tiny details that would have been invisible to a visiting researcher or in laboratory experiments. Wojciehowski's (2015) account of diakresis - the process through which, as we watch, we separate out what is salient enough to enter into our conscious awareness - also helped me to consider what 2-yearold viewers may be doing. Adult viewers know (or think they know) what is narratively salient as they watch; 2-year-olds may not, but this does not merely mean that they 'make mistakes' or 'miss out' on features that 'really are' salient to the narrative. What 2-year-olds are undoubtedly doing as they watch with focused attention, is separating out what is salient for them. As they get older, their memory capacity increases, they see more movies and acquire wider knowledge of their culture, and they will refine their ideas about salience. But it was clear from the children's pointing and excited comments that they were already using diakresis as a mechanism for making sense of enough bits of what they were watching to sustain their continued attention.

I have long been interested in how movie viewers negotiate the modality status of what they watch. I take this concept from a chapter in Hodge and Tripp's 1986 book Children and Television. Drawing on linguistic theory, they propose that the question of whether or not children believe that what they see on television is 'real' could more usefully be approached through the concept of 'modality', as used in linguistics to 'indicate degrees of certainty of a message' (Hodge and Tripp, 1986: 104). Because they are focused purely on television, Hodge and Tripp go beyond the focus of Kress and van Leeuwen's (2006: Chapter 5) later discussion of modality judgements, which is concerned almost entirely with still images. Their chapter remains useful in its account of modality judgements as a way of calibrating the assumed reality status of movies, as opposed to many scholars' continued insistence on making simple 'real versus not-real' 
distinctions (for example, Li et al., 2015), which has encouraged some scholars to make the condescending judgement that when children do not seem able to make this distinction, they must be 'confused' about the relationship between representations of scenes in movies or still images and real life (for example, Troseth, 2010).

But in this research, I saw how 2-year-olds' modality judgements are deliberately, though unselfconsciously, fostered in a playful, adventurous pattern both by adult coviewers and by movies themselves. The world in which 2-year-olds are immersed is one of fluctuating behavioural modes, where they can negotiate - or ignore - agendas set by adults or by texts. In the case of movie-watching, the adults may model watching quietly and seriously; they may encourage watching playfully, commenting on and even imitating actions on the screen; they may be talking to each other and taking no notice of what the children are doing; or they may not even be in the room. At the same time, 2-year-olds have their own varied agendas for movie-watching, ranging from focused attention through playful engagement to ignoring the screen altogether. Each of these modes has a bearing on reality-status, not only of what is being watched, but also on associated comments and behaviour. Woolley (1997: 991) points out that 'both children and adults entertain fantastical beliefs and also engage in magical thinking', and urges that we should think in terms of 'a continuum of ontological commitment to what we think the world is really like'. A later paper (Sharon and Woolley, 2004: 308) although based, again, on 3-6-year-olds - argues that, 'rather than having misplaced the boundary between real and fantastical entities [that is, being 'confused'], young children are still in the process of actively constructing it'. But 'active construction' implies individual effort: an important dimension of the twins' exploration of modality was its sociable playfulness. The innumerable games and rituals that parents and carers play with children, from peekaboo onwards, are ways of safely exploring emotions, desires, jeopardy and security, identities, ethics, metaphor - and modality (Edmiston, 2008), within the pleasurable safety of intersubjectivity (Trevarthen, 2005). Edmiston takes from performance theory the idea of the provisionality of play: that it is a context in which we see the world as dynamic and changing. This can be seen clearly in 2-yearolds' avid experimentation with the boundaries of the real.

\section{Implications for early years research and for media industries}

Where educators and psychologists have looked at infants' and toddlers' relationships with movies, it is usually with an eye to their later performance as learners or as social actors (for example, Anderson et al., 2001; Jennings et al., 2009; Lauricella et al., 2011; Linebarger and Vaala, 2010). Those few who have attempted to investigate how children cope with the formal features of movies have usually been constrained by limited accounts of what those features are, and of what that learning might entail (for example, Hoffner et al., 1989; Lang et al., 1993; Smith et al., 1985). I find it strange that, even a century after the invention of movies, the many scholars who have provided detailed and inspirational analyses of children's early learning and their social, cultural and imaginative development, refer to family activities, to books, toys and games, to siblings and friends, but almost never to movies (for example, Bruner, 1990; Edmiston, 2008; Lancaster, 2003; Nelson, 1998; Prout, 2005; Trevarthen, 1995). I began to see the twins' viewing behaviour not merely as a route to recognizing and interpreting the formal features of movies, but also as a way of expanding their opportunities for thought and reflection on human behaviour, imaginative possibilities, causal chains and the modal status of representations. 
Although some movies offer children extraordinarily rich and fascinating experiences, it is noticeable that an enormous amount of movie production for very young children stays within a relatively narrow set of conventions. There is a belief - not borne out in my research - that to appeal to this age group, movies should always be cheerful, colourful and animated - using simplified figures with exaggerated features. I was interested to see that the interest in formal innovation that primary teachers had reported to me was also evident in the twins' viewing practices, the most remarkable example being their extended interest - through more than twenty viewings - in the short film Animatou (Luyet, Switzerland, 2007). There is a case for industry research and investment in online channels, or DVD anthologies, of a more stylistically and modally diverse range of short movies for very young children.

\section{Conclusion}

Others who have studied children and movies have noted some of the same phenomena that I have observed: intense attention, emotional responses, co-viewing with family members, decided preferences and dedicated re-viewing (for example, Anderson and Hanson, 2010; Barr et al., 2008; Courage and Setliff, 2010; Gola and Calvert, 2011; Pempek et al., 2010). But because I have studied these as potential indicators of the processes of learning how to watch, and could do so as a close family member, while using extensive video evidence, my interpretations are different from those who have had other research questions and used other methods. I see intense attention and demands to re-view as evidence of children's serious investment in trying to understand movies more fully. Wanting to reach the levels of understanding evinced by their co-viewers is a key element of this commitment. Seeing their 'expectations of significance' as driven by innate emotions such as seeking, fear and joy indicates that initial limitations on understanding do not necessarily block the urge to find out more. The concepts of diakresis and embodied simulation usefully account for children's interim and sometimes wayward interpretations of movies, but also explain how they can happily continue to watch something they only partially understand. Children's imaginative capacities are exercised by movies, and encourage them to address the concept of alternative realities. Their growing ability to make modality judgements links closely to their and their co-viewers' playful relationship to the screen and the playful scenarios offered by many movies. Their ability to follow and understand narrative is developed by re-viewing, by the talk of co-viewers, the development of memory and, we must assume, a growing familiarity with the symbolic systems that movies use to convey meaning. But 2-year-olds' efforts to understand these systems are rarely recognized or respected. My argument is that learning how to understand movies is a real and significant achievement in the lives of any 2-year-olds that have access to them. I have sought to provide a better understanding of cultural experiences that have been relatively neglected, despite their important implications for human development and learning. While I have some sympathy for the forms of film education that Bergala describes, I believe that they seriously underestimate the knowledge, understanding and skills that children and young people bring to the subject.

\section{Notes on the contributor}

Cary Bazalgette worked at the British Film Institute from 1979 to 2007, having been a teacher of English and film-making in London secondary schools. She wrote and edited a number of classroom resources for media education, and published and spoke 
widely on this topic in the UK and around the world. As Head of BFI Education from 1999 to 2006, she led the development of new approaches to teaching and learning about moving-image media for the 3-14 age group. She recently completed a PhD at UCL Institute of Education, based on research into preschool children's encounters with moving-image media.

\section{References}

Anderson, D.R. and Hanson, K.G. (2010) 'From blooming, buzzing confusion to media literacy: The early development of television viewing'. Developmental Review, 30 (2), 239-55.

Anderson, D.R., Huston, A.C., Schmitt, K.L., Linebarger, D.L. and Wright, J.C. (2001) 'Early childhood television viewing and adolescent behavior: The recontact study'. Monographs of the Society for Research in Child Development, 66 (1), 1-147.

Barr, R., Zack, E., Garcia, A. and Muentener, P. (2008) 'Infants' attention and responsiveness to television increases with prior exposure and parental interaction'. Infancy, 13 (1), 30-56

Barthes, R. (1977) Image, Music, Text. Trans. Heath, S. London: Fontana Press.

Bergala, A. (2017) 'The Cinema Hypothesis' - YouTube video of talk given at the BFI, 3 February 2017. Online. https://www.youtube.com/watch?v=COH74quOWJ8 (accessed 11 March 2018).

Branigan, E. (1992) Narrative Comprehension and Film (Sightlines). London: Routledge.

Britton, J. (1970) Language and Learning. Harmondsworth: Penguin Books.

Bronfenbrenner, U. (1977) 'Toward an experimental ecology of human development'. American Psychologist, 32 (7), 515-31.

Bruner, J. (1990) Acts of Meaning. Cambridge, MA: Harvard University Press.

Carroll, N. (2010) 'Movies, the moral emotions, and sympathy'. Midwest Studies in Philosophy, 34 (1), 1-19.

Courage, M.L. and Setliff, A.E. (2010) 'When babies watch television: Attention-getting, attentionholding, and the implications for learning from video material'. Developmental Review, 30 (2), 220-38.

Damasio, A. (2000) The Feeling of What Happens: Body, emotion and the making of consciousness. London: Vintage Books.

Darwin, C. (1877) 'A biographical sketch of an infant'. Mind, 2 (7), 285-94.

Edmiston, B. (2008) Forming Ethical Identities in Early Childhood Play. London: Routledge.

Freire, P. (1970) Pedagogy of the Oppressed. Trans. Ramos, M.B. New York: Continuum.

Gallese, V. (2001) 'The "shared manifold" hypothesis: From mirror neurons to empathy'. Journal of Consciousness Studies, 8 (5-7), 33-50.

Gallese, V. and Lakoff, G. (2005) 'The brain's concepts: The role of the sensory-motor system in conceptual knowledge'. Cognitive Neuropsychology, 22 (3-4), 455-79.

Gallese, V. and Sinigaglia, C. (2011) 'What is so special about embodied simulation?'. Trends in Cognitive Sciences, 15 (11), 512-19.

Gola, A.A.H. and Calvert, S.L. (2011) 'Infants' visual attention to baby DVDs as a function of program pacing'. Infancy, 16 (3), 295-305.

Halliday, M.A.K. (1975) Learning How to Mean: Explorations in the development of language. London: Edward Arnold.

Hancock, R. and Gillen, J. (2007) 'Safe places in domestic spaces: Two-year-olds at play in their homes'. Children's Geographies, 5 (4), 337-51.

Hodge, B. and Tripp, D. (1986) Children and Television: A semiotic approach. Cambridge: Polity Press.

Hoffner, C., Cantor, J. and Thorson, E. (1989) 'Children's responses to conflicting auditory and visual features of a televised narrative'. Human Communication Research, 16 (2), 256-78.

Jennings, N.A., Hooker, S.D. and Linebarger, D.L. (2009) 'Educational television as mediated literacy environments for preschoolers'. Learning, Media and Technology, 34 (3), 229-42.

Jordan, A.B. (2006) 'Make yourself at home: The social construction of research roles in family studies'. Qualitative Research, 6 (2), 169-85.

Kissel, B.T. (2011) "'That ain't no Ninja Turtles": The prevalence and influence of popular culture in the talk and writing of prekindergarten children'. NHSA Dialog, 14 (1), 16-36.

Kress, G. and van Leeuwen, T. (2006) Reading Images: The grammar of visual design. 2nd ed. London: Routledge. 
Lancaster, L. (2001) 'Staring at the page: The functions of gaze in a young child's interpretation of symbolic forms'. Journal of Early Childhood Literacy, 1 (2), 131-52.

Lancaster, L. (2003) 'Moving into literacy: How it all begins'. In Hall, N., Larson, J. and Marsh, J. (eds) Handbook of Early Childhood Literacy. London: SAGE Publications, 145-53.

Lang, A., Geiger, S., Strickwerda, M. and Sumner, J. (1993) 'The effects of related and unrelated cuts on television viewers' attention, processing capacity, and memory'. Communication Research, 20 (1), 4-29.

Lauricella, A.R., Gola, A.A.H. and Calvert, S.L. (2011) 'Toddlers' learning from socially meaningful video characters'. Media Psychology, 14 (2), 216-32.

Lealand, G. (1998) 'Where do snails watch television? Preschool television and New Zealand children'. In Howard, S. (ed.) Wired-Up: Young people and the electronic media. London: UCL Press, 1-17.

Lemish, D. and Rice, M.L. (1986) 'Television as a talking picture book: A prop for language acquisition'. Journal of Child Language, 13 (2), 251-74.

Li, H., Boguszewski, K. and Lillard, A.S. (2015) 'Can that really happen? Children's knowledge about the reality status of fantastical events in television'. Journal of Experimental Child Psychology, 139, 99-114.

Linebarger, D.L. and Vaala, S.E. (2010) 'Screen media and language development in infants and toddlers: An ecological perspective'. Developmental Review, 30 (2), 176-202.

Marsh, J. (2000) 'Teletubby tales: Popular culture in the early years language and literacy curriculum'. Contemporary Issues in Early Childhood, 1 (2), 119-33.

Moses, A.M. (2008) 'Impacts of television viewing on young children's literacy development in the USA: A review of the literature'. Journal of Early Childhood Literacy, 8 (1), 67-102.

Nelson, K. (1998) Language in Cognitive Development: Emergence of the mediated mind. Cambridge: Cambridge University Press.

Panksepp, J. (2004) Affective Neuroscience: The foundations of human and animal emotions. Oxford: Oxford University Press.

Parry, B. (2013) Children, Film and Literacy. Basingstoke: Palgrave Macmillan.

Pempek, T.A., Kirkorian, H.L., Richards, J.E., Anderson, D.R., Lund, A.F. and Stevens, M. (2010) 'Video comprehensibility and attention in very young children'. Developmental Psychology, 46 (5), 1283-93.

Piaget, J. (1929) The Child's Conception of the World. Trans. Tomlinson, J. and Tomlinson, A. London: Routledge and Kegan Paul.

Plowman, L. and Stevenson, O. (2013) 'Exploring the quotidian in young children's lives at home'. Home Cultures, 10 (3), 329-47.

Plowman, L., Stevenson, O., Stephen, C. and McPake, J. (2012) 'Preschool children's learning with technology at home'. Computers and Education, 59 (1), 30-7.

Prout, A. (2005) The Future of Childhood: Towards the interdisciplinary study of children. London: Routledge.

Richmond, J. (ed.) (2017) Harold Rosen: Writings on life, language and learning, 1958-2008. London: UCL Institute of Education Press.

Rowe, D.W. (2008) 'Social contracts for writing: Negotiating shared understandings about text in the preschool years'. Reading Research Quarterly, 43 (1), 66-95.

Sharon, T. and Woolley, J.D. (2004) 'Do monsters dream? Young children's understanding of the fantasy/reality distinction'. British Journal of Developmental Psychology, 22 (2), 293-310.

Shegar, C. and Weninger, C. (2010) 'Intertextuality in preschoolers' engagement with popular culture: Implications for literacy development'. Language and Education, 24 (5), 431-47.

Smith, R., Anderson, D.R. and Fischer, C. (1985) 'Young children's comprehension of montage'. Child Development, 56 (4), 962-71.

Storm-Mathisen, A. (2016) 'Grasping children's media practices: Theoretical and methodological challenges'. Journal of Children and Media, 10 (1), 81-9.

Thomson, R., Hadfield, L., Kehily, M.J. and Sharpe, S. (2012) 'Acting up and acting out: Encountering children in a longitudinal study of mothering'. Qualitative Research, 12 (2), 186-201.

Trevarthen, C. (1995) 'The child's need to learn a culture'. Children and Society, 9 (1), 5-19.

Trevarthen, C. (2005) '"Stepping away from the mirror: Pride and shame in adventures of companionship": Reflections on the nature and emotional needs of infant intersubjectivity'. In Carter, C.S., Ahnert, L., Grossmann, K.E., Hrdy, S.B., Lamb, M.E., Porges, S.W. and Sachser, N. (eds) Attachment and Bonding: A new synthesis (Dahlem Workshop Report 92). Cambridge, MA: MIT Press, 55-84. 
Troseth, G.L. (2010) 'Is it life or is it Memorex? Video as a representation of reality'. Developmental Review, 30 (2), 155-75.

Weir, R.H. (1970) Language in the Crib. The Hague: Mouton.

Whitney, C. (2010) 'A learning journey'. In Bazalgette, C. (ed.) Teaching Media in Primary Schools. London: SAGE Publications, 75-84.

Wojciehowski, H.C. (2015) 'The floating world: Film narrative and viewer diakrisis'. In Coëgnarts, M. and Kravanja, P. (eds) Embodied Cognition and Cinema. Leuven: Leuven University Press, 115-38.

Wollen, P. (1998) Signs and Meaning in the Cinema. Expanded ed. London: British Film Institute. Woolley, J.D. (1997) 'Thinking about fantasy: Are children fundamentally different thinkers and believers from adults?'. Child Development, 68 (6), 991-1011. 